\title{
Aliskiren and L-carnitine attenuate isoproterenol-induced cardiac hypertrophy via targeting IL-6/JAK2/STAT3/SOCS3 signaling pathway
}

\author{
Maryam Hassaan1, Amany Balah2, Nayira A. Abdel Baky2* \\ ${ }^{1}$ Egyptian Ministry of Health and Population, Cairo, Egypt. \\ ${ }^{2}$ Department of Pharmacology and Toxicology, Faculty of Pharmacy (Girls), Al-Azhar University, Cairo, Egypt \\ *Correspondence e-mail, nayiraabdelbaky@yaho.com; nayiraabdelbaky.pharmg@azhar.edu.eg
}

\begin{abstract}
This research was designed to assess the inhibitory action of aliskiren, L-carnitine, and their combined treatment on JAK2/STAT3/SOCS3 signaling pathway in cardiac hypertrophy induced by isoproterenol injection in rats. Wistar rats were injected with isoproterenol $(5 \mathrm{mg} / \mathrm{kg} /$ day $)$ for 15 days for induction of cardiac hypertrophy. Hypertrophied animals were concurrently treated daily with aliskiren (50 $\mathrm{mg} / \mathrm{kg}$ ) and $/$ or L-carnitine $(200 \mathrm{mg} / \mathrm{kg})$. Either L-carnitine or aliskiren treatment significantly reduced the elevated relative heart weight with a concomitant reduction in brain natriuretic peptide, creatine kinase-MB, and troponin $\mathrm{T}$ in isoproterenol treated animals. Additionally, L-carnitine and/or aliskiren treatment significantly reduced myocardial interleukin-6, lipid peroxidation, and markedly increased glutathione content. Aliskiren and/or L-carnitine treatment also attenuated myocardial fibrosis as evidenced by the significant decrease in myocardial collagen I and transforming growth factor- $\beta 1$. The biochemical results were further confirmed by the improvement in myocardial histopathological architecture. Interestingly, aliskiren and Lcarnitine treatment down-regulated the expression of JAK2, STAT3, and SOCS3 in hypertrophied animals. Conclusively, aliskiren/L-carnitine regimen may ameliorate cardiac hypertrophy induced by isoproterenol through mitigating oxidative stress, inflammation, and IL-6/JAK2/STAT3/SOCS3 pathway.
\end{abstract}

Keywords: JAK2/STAT3; SOCS3; Aliskiren; L-carnitine; Cardiac Hypertrophy.

\section{INTRODUCTION}

Cardiac hypertrophy is an intermediate stage prior to heart failure, a highly refractory heart disorder, which represents a driving cause of global mortality 1,2 . Targeting cardiac hypertrophy was proposed to be a possible strategy to stop the progress of heart failure ${ }^{3}$. However, despite the increased understanding of the pathogenesis of cardiac hypertrophy, evolution in treatment stays stagnant in the last years, mainly due to the participation of many molecular pathways in its pathogenesis. The Janus Kinase/Signal Transducer and Activator of Transcription (JAK/STAT) pathway, is among the eminent signaling pathways implicated in hypertrophy pathogenesis ${ }^{4}$. It is involved in regulation of different genes expression that encodes ligands involved in proliferation, inflammation, immune responses, angiogenesis, and cell death ${ }^{5-7}$. Thus the development of therapeutic approaches that focus on modulation of JAK/STAT pathway is pivotal.

The three master parts of JAK/STAT pathway are; a cell membrane receptor, JAK, and STAT proteins ${ }^{8}$. JAK family consists of four proteins ${ }^{9}$, while seven members of STAT are recognized in mammals ${ }^{10}$. JAK/STAT pathway is regulated via the suppressor of cytokine signaling (SOCS) proteins ${ }^{11}$. Different ligands as interleukins, interferon, and growth factors activate JAKs and enhance their kinase activity with its downstream STATs ${ }^{12}$. One of the important ligands that also activate JAK/STAT/SOCS is angiotensin II (Ang II) ${ }^{13-15}$, the principal executor molecule of renin-angiotensin aldosterone system (RAAS) and the chief player in the pathogenesis of cardiac hypertrophy ${ }^{16}$.

Cardiac remodeling therapy focuses on the inhibition of RAAS to delay the progress of myocardial hypertrophy and consequently heart failure. Aliskiren is a potent renin inhibitor used in management of hypertension and related cardiovascular diseases including myocardial hypertrophy ${ }^{17-19}$. Despite the consensus of the cardioprotective effect of aliskiren against cardiac hypertrophy, its full mechanism has not been fully established yet. Recently, aliskiren was shown to ameliorate isoproterenol-induced cardiac hypertrophy via modulation of calcium calmodulin-

Cite this article: Hassan, M., Balah, A., Abdelbaky, N. Aliskiren and L-carnitine attenuate isoproterenol-induced cardiac hypertrophy via targeting IL-6/JAK2/STAT3/SOCS3 signaling pathway. Azhar International Journal of Pharmaceutical and Medical Sciences, 2021;1(2):72-87. 
dependent protein kinase delta isoform expression and apoptosis inhibition ${ }^{19}$. However, other molecular targets for aliskiren remains incompletely explored.

L-carnitine is a natural compound present in most mammalian tissues ${ }^{20}$. L-carnitine primarily is responsible for translocating long-chain fatty acylcoenzyme A to mitochondria to be degraded by $\beta$ oxidation ${ }^{21}$. Indeed, L-carnitine was suggested for treating different cardiac disorders including cardiac hypertrophy, presumably via reducing oxidative stress and inflammation ${ }^{22-25}$. Recently, L-carnitine was documented to modulate STAT3 expression ${ }^{26}$.

Up till now, information is unavailable about aliskiren or L-carnitine effect on JAK2/STAT3/SOC3 signaling in hypertrophied heart. Hence, this research was planned to assess the effect of L-carnitine in potentiating the cardioprotective action of aliskiren against myocardial hypertrophy, and to shed the light on their role in targeting JAK2/STAT3/SOCS3 signaling pathway.

\section{MATERIALS AND METHODS}

\subsection{Chemicals}

Aliskiren was provided by Novartis Pharma AG (Basel, Switzerland). L-carnitine was obtained from Mepaco-MEDIFOOD (Cairo, Egypt). Isoproterenol was purchased from Sigma-Aldrich Chemical Co (St. Louis, MO, USA). Other used chemicals were of analytical grade.

\subsection{Animals}

Fifty male Wistar rats $(200 \pm 20 \mathrm{~g})$ were provided from the National Institute for Research, Cairo, Egypt. Rats were reserved at precise controlled housing conditions. Animals were left for seven days before the start of any experimental processes for acclimatization. Standard rat chow and water were provided to the animals ad libitum. The Animal Ethics Committee in the Faculty of Pharmacy, Al-Azhar University, Egypt, approved the experimental design of this research (Approval number: 77/2016).

\subsection{Induction of cardiac hypertrophy and treatment protocol}

Cardiac hypertrophy was established depending on the method of Chowdhury et al. (2013) 27. Concisely, animals were daily administrated intraperitoneal (I.P.) injection of $5 \mathrm{mg} / \mathrm{kg}$ isoproterenol for 15 days. Control rats were injected I.P. with normal saline for 2 weeks. Rats were haphazardly assigned into 5 groups (10 rats/group) as follow; Group 1 (Control): rats were injected with normal saline; Group 2 (ISO): rats I.P. injected with isoproterenol; Group 3 (ISO+ALS): rats were orally administrated aliskiren (50 mg/kg/day for 2 week) ${ }^{28}$ with concurrent I.P. injection of isoproterenol; Group 4 (ISO+L-Car): rats were orally administrated Lcarnitine $\left(200 \mathrm{mg} / \mathrm{kg} /\right.$ day for 2 weeks ${ }^{29}$ with concurrent I.P. injection of isoproterenol; Group 5 (ISO+ALS+L-Car): rats were orally administrated aliskiren and L-carnitine (the same dose) with concurrent I.P. injection of isoproterenol

After 24 hours of last dose administration, blood was collected under mild anesthesia by retroorbital sinus puncture. Blood was centrifuged, and serum was collected and kept at $-80^{\circ} \mathrm{C}$ till utilized for biochemical assays. Animals were sacrificed, hearts were quickly collected, washed, dried, and their weights were measured. Next, parts of the heart samples were homogenized $(10 \% \mathrm{w} / \mathrm{v})$ in phosphatebuffered saline, the clear homogenate was used for measuring different biochemical parameters. Other heart samples were placed in $10 \%$ formalin for histological examination while last parts were snap frozen to be used for western blot analysis.

\subsection{Determination of relative heart weight}

The weights of rats as well as their heart weight were recorded. The relative heart weight was determined and utilized as an evidence for cardiac hypertrophy.

\subsection{Enzyme-linked immunosorbent assay (ELISA)}

Markers for myocardial damage including serum creatine kinase-MB (CK-MB), troponin T, and myocardial brain natriuretic peptide (BNP) were assessed using ELISA kits (MyBioSource, San Diego, USA) depending on the instructions of manufacturer. Myocardial interleukin-6 (IL-6) was assessed using ELISA kit as stated by the manufacturer's recommendation (R\&D Systems Inc., Minneapolis, MN, USA).

\subsection{Oxidative stress measurement}

Concentration of malondialdehyde (MDA) was measured by thiobarbituric acid method. It is based on the reaction of malondialdehyde with TBA at $98{ }^{\circ} \mathrm{C}$. TBARs were determined colorimetrically using assay kit for lipid peroxidation (MDA) (abcam, MA, USA) depending on the instructions of manufacturer. Myocardial glutathione (GSH) content was measured using commercially available kit (Biodiagnostic, Giza, Egypt).

\subsection{Assessment of cardiac fibrosis}

Myocardial transforming growth factor- $\beta 1$ (TGF- $\beta 1$ ) was determined utilizing ELISA kit 
according to manufacturer's recommendations (MyBioSource, San Diego, USA). Collagen I in heart tissue was measured using rat collagen type I ELISA kits (Cusabio Technology, USA). The colored product absorbance was recorded using a microplate reader set to $450 \mathrm{~nm}$.

\subsection{Immunohistochemical analysis}

Tissue preparation and immunohistological analysis were performed as described previously ${ }^{30}$, using antibodies against rat collagen I. Briefly, heart sections were deparaffinized in xylene and rehydrated in graded ethanol. The antigenicity of the protein was enhanced with microwaves in citrate buffer (PH 6.0) at $98^{\circ} \mathrm{C}$ for $15 \mathrm{~min}$ and washed with PBS. Sections then were treated with $3 \%$ hydrogen peroxide for 10 min. After that sections were washed with PBS and incubated with the primary antibody for anti-collagen I (abcam company, Cambridge) at $4^{\circ} \mathrm{C}$ for 12 hours, washed, and finally stained with polymer HRP detection system. The sections were reacted in a 3-3diaminobenzidine solution for $60 \mathrm{~s}$ to visualize immunolabeling, and finally counterstained with haematoxylin and mounted.

\subsection{Western blot analysis}

Phosphorylation of myocardial JAK2 and STAT3 proteins as well as SOCS3 expression were assessed using Western blotting analysis. After blotting, blocking in 5\% bovine serum albumin in Trisbuffered saline containing $0.05 \%$ Tween (TBST) was performed. The membrane was processed with primary antibodies against p-JAK2, p-STAT3, and SOCS3 (1:1,000) (Cell Signalling Technology, Beverly, MA, USA) diluted in 1x TBST-buffer for 12 hours at $4{ }^{\circ} \mathrm{C}$, afterwards, membrane was rinsed and incubated for one hour at room temperature with secondary antibody diluted in $1 x$ TBST-buffer $(1: 10,000)$ before signal detection using enhanced chemiluminescence (ECL) system. The phosphorylation residue sites of the antibodies that were used in Western blot analysis are the main two tyrosine residues (Tyr1007 and Tyr1008) in the kinase activation loop of JAK2 ${ }^{31}$ and Tyr705 for STAT3 ${ }^{32-34}$.

\subsection{Histopathological examination}

Heart tissue was fixed in $10 \%$ buffered formalin, dehydrated in ascending dilutions of ethanol, then embedded inxylene-paraffin. Ventricular sections $(3 \mu \mathrm{m})$ were cut and stained with haematoxylin and eosin (H\&E) reagent ${ }^{35}$, then visualized under a microscope at $400 \times$ magnification.

\subsection{Statistical analysis}

Analysis of data was done by SPSS (version 21) statistical software. All results were expressed as mean \pm S.D. Multiple comparisons were performed using ANOVA followed by Bonferroni multiple comparisons test as a post ANOVA test. Significant differences between compared groups were established at a $P$ values less than 0.05 .

\section{RESULTS}

\subsection{Aliskiren, L-carnitine, and their combined treatment attenuated macroscopic alteration in isoproterenol-treated rats}

Isoproterenol-treated rats appeared weaker and fatigued at the end of the study, meanwhile, animals that recieved aliskiren/L-carnitine combination regimen showed just as lowest of such symptoms. Aliskiren or L-carnitine did not markedly modify body weight gain in hypertrophied animals in comparison to control group. A substantial increase $(52 \%)$ in heart weight was shown in isoproterenol hypertrophied animals versus normal rats $(\mathrm{p}<0.05)$. Aliskiren, L-carnitine and their combination protocol markedly decreased this increase in heart weight by $19 \%, 10.5 \%$, and $28 \%$, respectively compared to isoproterenol-hypertrophied rats (Table 1).

Table 1: Effects of aliskiren and/or L-carnitine treatment on isoproterenol-induced changes on body weight and heart weight in hypertrophied rats.

\begin{tabular}{|l|l|l|l|}
\hline \multicolumn{3}{|l|}{ Groups } & \multicolumn{2}{|l|}{\begin{tabular}{l}
\multicolumn{2}{|c|}{ Initial } & Heart weight \\
Final
\end{tabular}} \\
\hline Control & $199 \pm 2.28$ & $221.8 \pm 10.03$ & $0.75 \pm 0.05$ \\
\hline ISO & $216.3 \pm 5.95$ & $236 \pm 11.40$ & $1.14 \pm 0.05^{*}$ \\
\hline ISO+ALS & $194 \pm 5.02$ & $221.2 \pm 12.02$ & $0.92 \pm 0.07^{* \pi}$ \\
\hline ISO+L-Car & $211.3 \pm 4.76$ & $230.5 \pm 12.52$ & $1.02 \pm 0.04^{* \pi}$ \\
\hline ISO+ALS+L-Car & $204 \pm 5.18$ & $233.8 \pm 9.02$ & $0.82 \pm 0.05^{\pi \varphi}$ \\
\hline
\end{tabular}

Results are represented as means \pm S.D $(\mathrm{n}=6) .{ }^{*} P<0.05$, versus control group, ${ }^{\pi} P<0.05$ versus isoproterenol group, ${ }^{\varphi} P<0.05$ versus $\mathrm{L}$-carnitine treated group respectively, using ANOVA followed by Bonferroni as a postANOVA test.

\subsection{Aliskiren, L-carnitine, and their combined treatment alleviate myocardial hypertrophy and ultrastructural changes in isoproterenol- hypertrophied rats}

Histological evaluation of myocytes structure was done utilizing H\&E staining to follow the impact of aliskiren and/or L-carnitine on myocardial histological architecture after isoproterenol treatment in rats (Figure 1A). In isoproterenol treated group, histological evaluation of the ventricles demonstrated 
focal degenerated hyalinized myocardium with focal infiltration of inflammatory cells and myofibroblasts proliferation. Treatment with L-carnitine reduced inflammatory cells infiltration and myofibroblast proliferation in myocardial tissues, meanwhile, treatment with aliskiren amended the aforementioned histopathological changes to a greater extent. The combination of aliskiren and L-carnitine altered all of the previously mentioned histological features, where the heart tissue of the combination protocol showed apparently normal myocardial muscle bundle with no inflammatory cell infiltration. The expression of fibrotic protein collagen I was also assessed by immunohistochemistry (Figure 1B). Collagen I expression was increased in isoproterenol treated group, with progressive subendocardial and interstitial fibrosis (arrow) and myofibroblast proliferation (star). The immunohistochemical staining of ventricular muscle of rat received isoproterenol and L-carnitine or aliskiren showed moderate myocardial cell degeneration and hyalinization with mild to moderate decrease in collagen I immunoreactivity (arrow), while in between degenerated and hyalinized bundle; there is still myofibroblast proliferation (star). Notably, rat treated with aliskiren and L-carnitine combination protocol showed nearly normal myocardial muscle bundle. Figure1C further confirms the hypertrophic effect of isoproterenol, where HW/BW ratio (index for hypertrophy) was markedly elevated by $44.7 \%$ in isoproterenol-treated rats compared to normal animals. Meanwhile, aliskiren or L-carnitine treatment significantly reduced $\mathrm{HW} / \mathrm{BW}$ in isoproterenol-treated rats by about $14.6 \%$, and $11.3 \%$, respectively compared to that of isoproterenol treated animals. Interestingly, L-carnitine co-treatment with aliskiren restored $\mathrm{HW} / \mathrm{BW}$ ratio to a normal control value (Figure 1C). Isoproterenol-treatment also significantly increased myocardial BNP level by $409 \%$ versus control group $(p<0.05)$. Aliskiren, Lcarnitine, and their combination protocol significantly lowered BNP level $(\mathrm{p}<0.05)$ by $73.9 \%, 63.9 \%$, and $75.6 \%$, respectively compared to isoproterenol hypertrophied rats (Figure 1D).

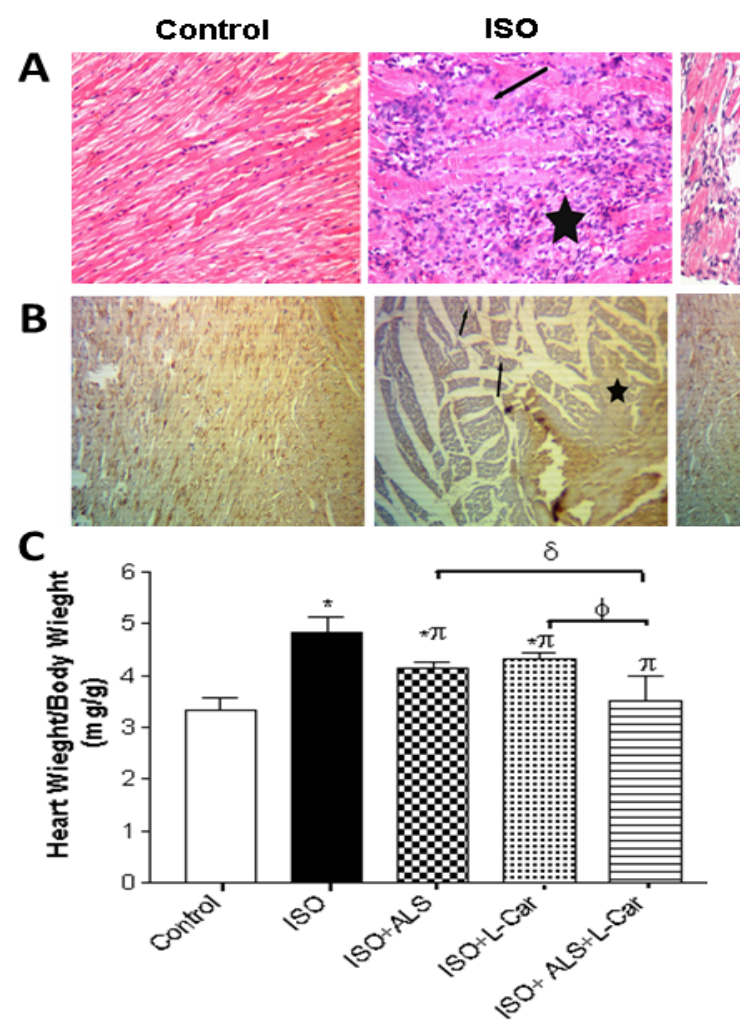

ISO+ALS

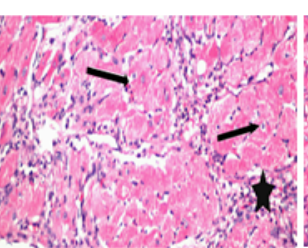

ISO+L-Car
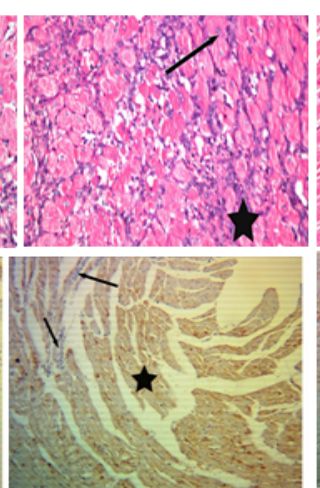

D

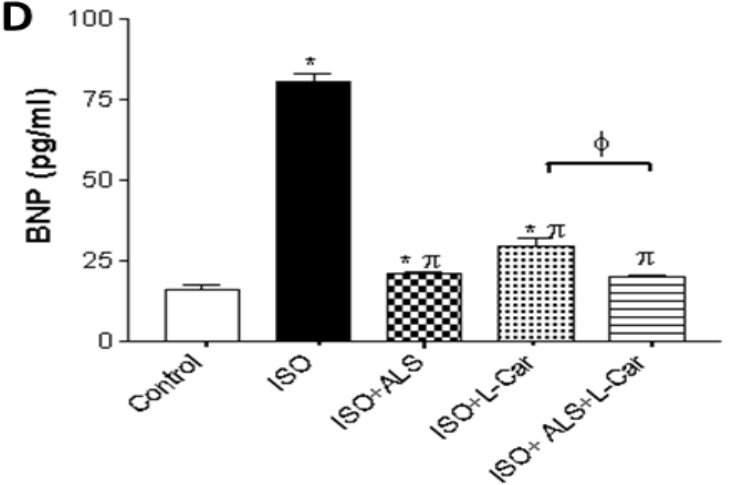

ISO+ALS+L-Car

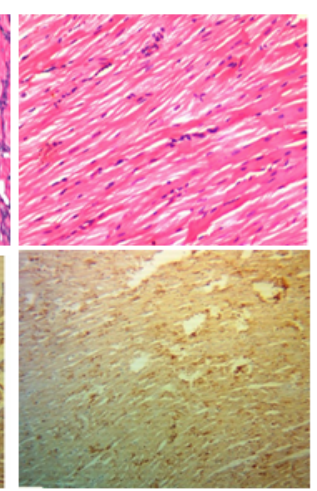

Figure 1: Effect of aliskiren, L-carnitine, and their combination on isoproterenol-induced cardiac hypertrophy in rats. (A) Light photomicrographs of rat ventricular sections stained with H\&E. (B) Illustrative images of immunohistochemical staining of collagen in cardiac sections (magnification, $\times 400 ; n=3$ /group), (C) relative heart weight, and (D) myocardial BNP level. Results are represented as mean $\pm S . D(n=6) .{ }^{*} P<0.05$ versus control group, ${ }^{\pi} P<0.05$ versus isoproterenol-hypertrophied group, ${ }^{\delta} P<0.05$ versus aliskiren treated group, ${ }^{\varphi} P<0.05$ versus $L-$ carnitine treated group, respectively, using ANOVA followed by Bonferroni as a post-ANOVA test 


\subsection{Aliskiren, L-carnitine, and their combined treatment reduced cardiac injury markers in isoproterenol-hypertrophied rats}

In the current study, isoproterenol treatment induced cardiac hypertrophy that was evidenced from the raise in serum $\mathrm{CK}-\mathrm{MB}$, and troponin $\mathrm{T}$ levels. Figure. 2A and 2B show that, isoproterenol-treatment significantly increased CK-MB (139.5\%), and troponin $\mathrm{T}(960 \%)$ compared to normal group. Aliskiren, L-carnitine, and their combination markedly reduced CK-MB by $41.4 \%, 28.9 \%$, and $46.2 \%$ and troponin $\mathrm{T}$ levels by $67.5 \%, 59.3 \%$, and $81.3 \%$, respectively versus isoproterenolhypertrophied rats.
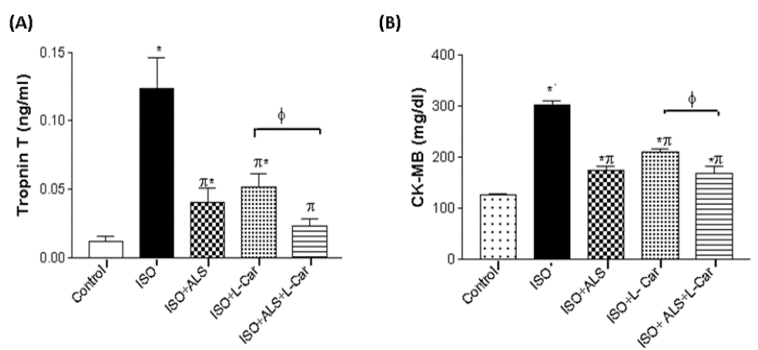

Figure 2: Effect of aliskiren, L-carnitine, and their combination on serum CK-MB (A), and troponin $\mathrm{T}(\mathrm{B})$ in isoproterenol-treated rats. Results are represented as mean \pm S.D. $(\mathrm{n}=6) .{ }^{*} P<0.05$ versus control group, ${ }^{\pi} P<$ 0.05 versus isoproterenol-hypertrophied group,${ }^{\varphi} P<0.05$ versus L-carnitine treated group, respectively, using ANOVA followed by Bonferroni as a post-ANOVA test

\subsection{Aliskiren, L-carnitine, and their combined treatment reduced oxidative stress and inflammation in isoproterenol-hypertrophied rats}

Figure 3A shows that, MDA was markedly greater $(\mathrm{p}<0.05)$ in isoproterenol hypertrophied animals $(686.2 \%)$ in comparison with control group. Aliskiren or L-carnitine treatment markedly reduced lipid peroxidation by $55.9 \%$ and $62.9 \%$, respectively versus isoproterenol-treated rats $(\mathrm{p}<0.05)$. Additionally, myocardial GSH of hypertrophied rats was significantly reduced by $44.3 \%$ versus normal group. L-carnitine or aliskiren markedly increased myocardial GSH in hypertrophied animals by $38.4 \%$ and $50.17 \%$, respectively as compared to isoproterenol-treated animals (Figure. 3B). The combination protocol produced more significant inhibitory effect on oxidative stress, where cotreatment of hypertrophied rats with L-carnitine and aliskiren markedly reduced MDA by $75.2 \%$ that was accompanied by significant elevation in myocardial GSH content by $67.5 \%$ compared to isoproterenoltreated group.

Additionally, inflammation in the heart tissue of hypertrophied animals was significantly increased as evidenced from the marked rise in myocardial IL6 level $(344.7 \%)$ in comparison with normal group. However, treatment with L-carnitine, aliskiren and their combination significantly reduced IL- 6 level by $38.2 \%, 48.6 \%$ and $54.7 \%$, respectively as compared to hypertrophied rats (Figure. 3C). Thus, aliskiren/Lcarnitine combination treatment significantly mitigated oxidative stress and inflammation to a greater range $(\mathrm{p}<0.05)$ than either aliskiren- or Lcarnitine- single treatment protocol.

(A)

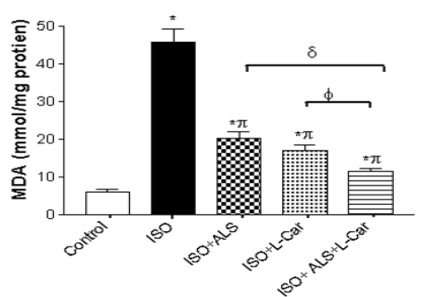

(B)

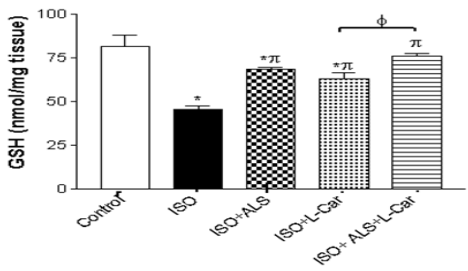

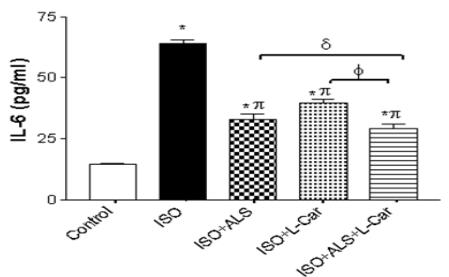

Figure 3: Effect of aliskiren, L-carnitine, and their combination on myocardial MDA (A), GSH (B), and IL-6 (C) in isoproterenolhypertrophied rats. Results are expressed as mean \pm S.D. $(n=6) . * P<0.05$ versus control, ${ }^{\pi} P<0.05$ versus isoproterenol-hypertrophied group, ${ }^{\delta} P<0.05$ versus aliskiren treated group, ${ }^{\varphi} P<0.05$ versus L-carnitine treated group, respectively, using ANOVA followed by Bonferroni as a post-ANOVA test. 


\subsection{Aliskiren, L-carnitine, and their combined treatment reduced myocardial fibrosis in isoproterenol-hypertrophied rats}

Figures 4 (A) and 4(B) show that, isoproterenol injection significantly increased myocardial TGF$\beta 1$ and collagen I content by $224.9 \%$ and $217 \%$, respectively in comparison with control rats $(\mathrm{p}<0.05)$. Treatment with aliskiren or L-carnitine

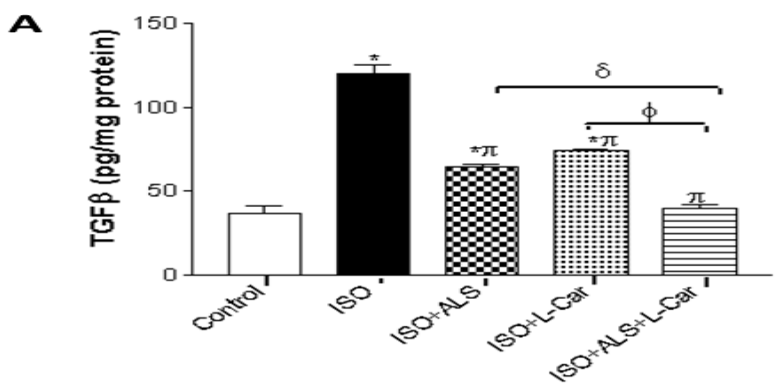

markedly decreased TGF- $\beta 1$ levels by $45.9 \%$, and $37.8 \%$, and collagen I by $51.33 \%$ and $43.8 \%$, respectively versus isoproterenol-hypertrophied animals

$(\mathrm{p}<0.05)$. Interestingly, combination regimen significantly reduced TGF- $\beta 1(66.7 \%)$ and collagen I $(63 \%)$ to a greater extent than either L-carnitine or aliskiren single treatment protocol compared to isoproterenol group.

B

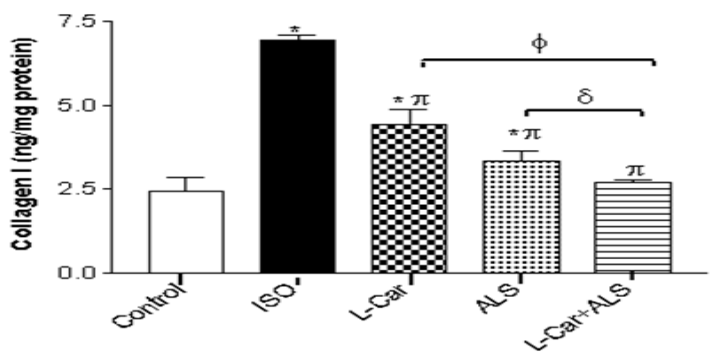

Figure 4: Effect of aliskiren, L-carnitine, and their combination on myocardial TGF- $\beta 1$ and collagen I content in isoproterenol-treated rats. ( $n=6$ /group). Results are expressed as mean \pm S.D. ${ }^{*} p<0.05$ versus control group, ${ }^{\pi} P<0.05$ versus isoproterenol-hypertrophied group, ${ }^{\delta} P<0.05$ versus aliskiren treated group, ${ }^{\varphi} P<0.05$ versus L-carnitine treated group, respectively, using ANOVA followed by Bonferroni as a post-ANOVA test

3.6. Effect of aliskiren, L-carnitine, and their combined treatment on p-JAK2, p-STAT3, and SOCS3 protein levels in isoproterenolhypertrophied rats

Figure 5A shows western blotting of p-JAK2, p-STAT3, and SOCS3 protein. Isoproterenol treatment significantly increased p-JAK2 (4.1 fold) and p-STAT3 (5 fold) in myocardial tissue in comparison with normal group. L-carnitine or aliskiren treatment markedly reduced JAK2 phosphorylation by $47.6 \%$ and $57.6 \%$ and STAT3 phosphorylation by $42.3 \%$ and $50 \%$, respectively versus isoproterenoltreated rats. Interestingly, L-carnitine co-treatment with aliskiren markedly decreased p-JAK2 (70\%) and p-STAT3 $(71 \%)$ in comparison to either single treatment protocol (Fig. 5B,5C). Expression of SOCS3 was also significantly increased after isoproterenol treatment (3.7 fold) compared to control group (Fig. 5D). Treatment with aliskiren or Lcarnitine significantly reduced SOCS3 protein expression by $49.2 \%$, and $45.2 \%$, respectively compared to isoproterenol hypertrophied group. Remarkably, the combination regimen significantly lowered SOCS3 expression to a greater extent $(60.8 \%)$ than either L-carnitine or aliskiren single treatment protocol. 

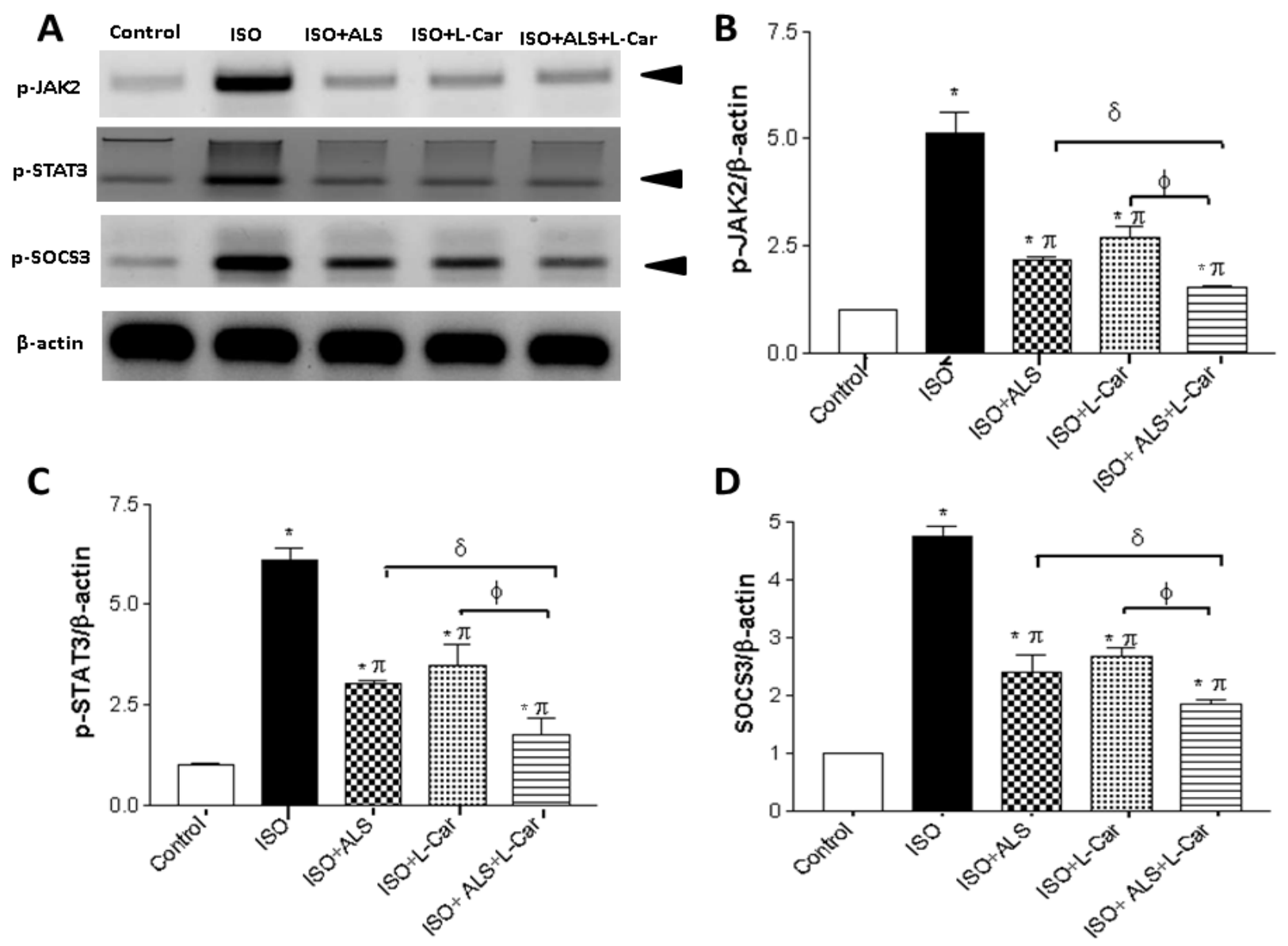

Figure 5: Effect of aliskiren, L-carnitine, and their combination on p-JAK2, p-STAT3, and SOCS3 protein levels in the hearts of isoproterenol-treated rats. A: Western blotting of p-JAK2, p-STAT3, and SOCS3 proteins. B-D: Histogram shows the relative level of p-JAK2, p-STAT3, and SOCS3 proteins. Data are presented as mean \pm S.D. $(\mathrm{n}=3) .{ }^{*} p<0.05$ versus control group, ${ }^{\pi} \mathrm{P}<0.05$ versus isoproterenol-hypertrophied group, ${ }^{\delta} \mathrm{P}<0.05$ versus aliskiren treated group, $\varphi \mathrm{P}<0.001$ versus L-carnitine treated group, respectively, using ANOVA followed by Bonferroni as a post-ANOVA test

\section{DISCUSSION}

For the first time this study revealed that, the ameliorating effect of L-carnitine/aliskiren against isoproterenol-induced cardiac hypertrophy and myocardial fibrosis is partly mediated via inhibition of JAK2/STAT3/SOCS3 pathway. Isoproterenoltreated rats exhibited hypertrophied myocardium that was evidenced from the elevated cardiac index (HW/BW) and increased myocardial injury markers; CK-MB, troponin T, and BNP. Hypertrophic effect of isoproterenol was also associated with myocardial fibrosis indicated by the significant elevation in myocardial collagen I and TGF- $\beta 1$, and further confirmed by the histological degeneration of myocardial structure. Our data are consistent with earlier reports which showed that, isoproterenol as $\beta$ adrenergic stimulant increases the release of cardiac markers indices 4,36,37, cell size and total collagen 38, and fibrosis 39. Aliskiren or L-carnitine single treatment protocol exhibited an ameliorative effect against isoproterenol-induced myocardial damage. Data from earlier studies documented the protective action of aliskiren 19, 40, 41, and L-carnitine 42-45 against experimental and clinical cardiac disorders. The alleviating action of aliskiren on the histopathological alterations was distinct than Lcarnitine, and was in accordance with its effect on cardiac markers level. Aliskiren cardioprotective effect depends, at least in part, on its inhibitory action on renin activity and consequently on Ang II level. Meanwhile, L-carnitine protective action is attributed to its antioxidant and anti-inflammatory effects. Interestingly, L-carnitine/aliskiren combination boosts more protective action than single treatment protocols as manifested by the significant lowering in myocardial injury markers, declined HW/BW ratio, and restoration of the normal histopathological structure. The combination regimen also showed more significant anti-fibrotic action than either 
aliskiren or L-carnitine single treatment protocol. The increase in collagen I content in myocardial tissue is a characteristic feature of fibrosis that occurs in cardiac hypertrophy and is partially mediated by TGF- $\beta 1^{46}$. Researchers have documented a rise in collagen I and collagen III synthesis due to $\beta$ adrenergic receptor activation of fibroblasts ${ }^{47}$. In heart diseases, cardiomyocytes are lost owing to necrosis, meanwhile, myofibroblasts activation takes place to launch restorative fibrosis as they are the main cells accountable for collagen and extracellular matrix deposition ${ }^{48}$. Myofibroblasts generate Ang II and fibrogenic growth factors that play a critical part in fibrosis and collagen I synthesis ${ }^{49}$. Aliskiren as a renin inhibitor, with its reducing effect on Ang II level, has been demonstrated to decrease deposition of collagen and myocardial fibrosis in different investigational models ${ }^{50-52}$. Mustafa et al. ${ }^{45}$ showed that, L-carnitine treatment decreased the transformation of fibroblasts to myofibroblasts, and restrained cardiac fibrosis. Also, L-carnitine was shown to reduce Ang II-mediated collagen release ${ }^{53}$. Additionally, the underlying mechanism for the attenuating effect of both drugs on cardiac fibrosis might also be in part due to their inhibitory action on TGF- $\beta 1$ expression ${ }^{51-54}$. These results are in line with our data in which either aliskiren or L-carnitine treatment markedly reduced myocardial TGF- $\beta 1$, collagen I expression and deposition, as well as cardiac fibrosis induced by isoproterenol treatment.

One of the key player mechanisms that participate in the progression of myocardial hypertrophy is oxidative stress ${ }^{55}$. Herein, we demonstrated an increase in myocardial MDA content accompanied by a reduction in GSH level in hypertrophied hearts. These data are in accordance with the increase in serum cardiac injury markers that can be elucidated by the elevated oxidative stress and the consequent lipid peroxidation, with a resultant elevation in enzyme outflow from cardiac cells into the serum ${ }^{56}$. Isoproterenol injection and its oxidative metabolism mediate the production of reactive oxygen species (ROS) and depress total cellular antioxidant capability ${ }^{57}$. Additionally, exacerbation of RAAS and the increase in Ang II level is another explanation for the massive production of ROS and the hypertrophic effect of isoproterenol on the heart tissue ${ }^{58,59}$.

Concordantly, treatment with L-carnitine, aliskiren, or their combination suppressed myocardial lipid peroxidation and increased GSH level. These findings are in line with several reports proving the ameliorating action of L-carnitine on oxidative stress and subsequent tissue injury, which might be explained by its free radical scavenging activity either directly or via decreasing its production, preserving mitochondrial electron transport chain efficiency, activating and increasing enzymatic and nonenzymatic antioxidant 22-24,60. Additionally, Lcarnitine is able to protect myocardial integrity via regulating intra-mitochondrial acyl-CoA/CoA percentage resulting in toxic compounds as well as free radicals elimination ${ }^{61}$. On the other hand, aliskiren, as a potent inhibitor of renin, thereby inhibiting RAAS and Ang II production, has been shown to decrease oxidative stress in different experimental models ${ }^{18,62,63}$. In the present study, cotreatment of aliskiren with L-carnitine potentially reduced oxidative stress in untreated hypertrophied rats confirming the suppressive action of aliskiren alone or its combination with L-carnitine on ROS production.

Inflammation represents one of the earliest processes that aid in the development of cardiac hypertrophy ${ }^{64}$. Our data clarified that, aliskiren or Lcarnitine treatment significantly lowered IL-6 level in isoproterenol hypertrophied hearts, yet, the combination regimen showed more significant antiinflammatory action in comparison to either aliskiren or L- carnitine alone. Our data is in line with the evident antioxidant activity seen in the combination protocol, as the main trigger for pro-inflammatory cytokines release are oxidative stress and ROS ${ }^{65,66}$. Indeed, inflammation and oxidative stress are connected inextricably because they create and magnify each other ${ }^{65}$. Other previous studies revealed that, aliskiren significantly reduced lipid peroxidation, inflammatory markers secretion and expression hence reduce the progression of tissue injury $18,62,67,68$. Meanwhile, L-carnitine has been documented to significantly reduce inflammatory cell infiltration in cardiac tissue ${ }^{60}$, as well as serum and myocardial IL- $1 \beta$ and TNF- $\alpha$ levels in coronary artery disease patients ${ }^{69}$, diabetic rats ${ }^{70}$, and in $\mathrm{N} \omega$ nitro-L-arginine methyl ester-treated rats ${ }^{71}$. Therefore, reduced IL-6 level in aliskiren/L-carnitine treated group could be attributed to the enhanced antioxidant and anti-inflammatory action of Lcarnitine and aliskiren.

JAK/STAT pathway is a cardio-protective signaling pathway against pathological stresses ${ }^{72}$. However, exaggerated stimulation of JAK/STAT pathway contributes to maladaptive responses and represents a crucial counterpart of the myocardial response to hypertrophy ${ }^{73,74}$. SOCS3 was known as target gene for the JAK2/STAT3 pathway, forming a negative-feedback loop to stop signal propagation 75. However, overexpression of SOCS3 intensify myocardial apoptosis and result in immense interstitial fibrosis ${ }^{76}$. On such basis, and to explain 
the molecular mechanisms for the protective action of aliskiren and L-carnitine on isoproterenol-induced cardiac hypertrophy, JAK2/STAT3/SOCS3 signaling was assessed as a putative mechanism.

Our findings indicated that, JAK2/STAT3 phosphorylation and the expression of SOCS3 were significantly increased in isoproterenol hypertrophied rats, participating in the pronounced elevation in TGF- $\beta 1$ and collagen I expression with the subsequent cardiac fibrosis. These data are in accordance with several previous reports 4,7,77. Actually, several previous studies revealed that SOCS3 expression was increased in many clinical disorders and animal models including cardiac hypertrophy in accordance with the enhanced expression of STAT3 ${ }^{74,75,78-80}$. The list of inducers of JAK2/STAT3/SOCS3 proteins in the heart is mounting; including several cytokines in addition to Ang II ${ }^{81-84}$. JAK2/STAT3/SOCS3 proteins are crucial participants in Ang II/AT1R signal transduction $^{5,84}$. Thus, the significant rise in p-JAK2, p-STAT3, and SOCS3 expression could be due to elevated IL-6 level and most importantly to the exacerbated RAAS due to isoproterenol treatment 19,59, 77 . Meanwhile, the anti-inflammatory activity of aliskiren ${ }^{50,67,68}$ and L-carnitine ${ }^{60,69,70}$, in addition to their established suppressive effect on Ang II level and AT1R expression ${ }^{50,84-86}$ assured the positive correlation between the reduced p-JAK2/pSTAT3/SOCS3 expression and the decreased myocardial TGF- $\beta 1$ level in this study. Thus, our data corroborate to literature, evidencing that, inhibition of JAK2/STAT3/SOC3 pathway might be a crucial mechanism to the mitigating action of aliskiren/Lcarnitine therapeutic regimen on myocardial hypertrophy.

\section{CONCLUSIONS}

Conclusively, our study highlighted that, the cardioprotective effect of aliskiren and L-carnitine might be mediated via their repressive effect on IL6/JAK2/STAT3/SOCS3 signaling pathway. This effect might be one of the contributing cardioprotective mechanisms besides inhibition of oxidative stress, inflammatory response, and the consequent mitigation of myocardial fibrosis. These findings are supportive for the use of aliskiren and Lcarnitine as a protective and therapeutic protocol rescuing the heart from hypertrophy and hence heart failure.

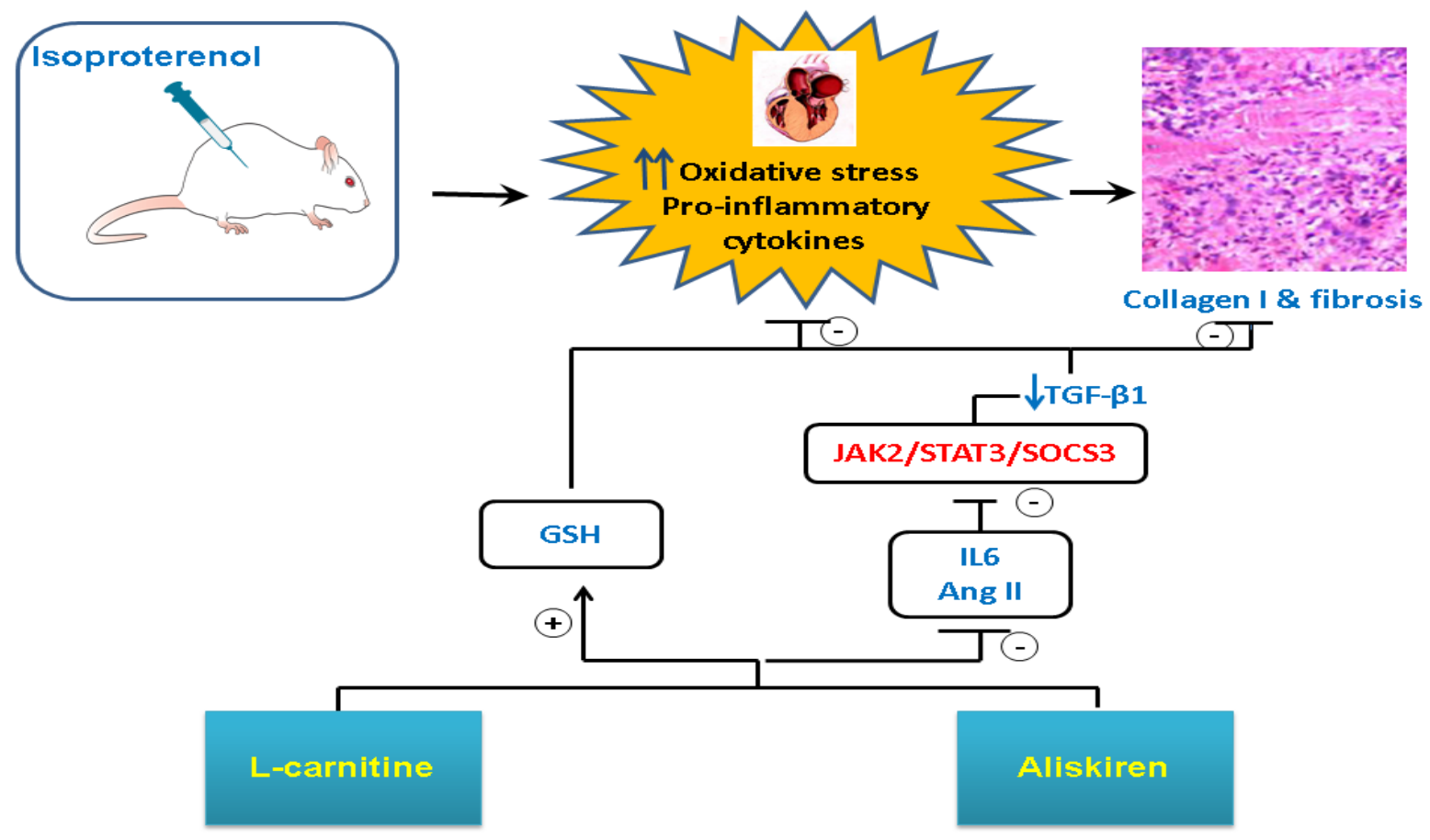

Figure 6: Schematic diagram for the protective effect of aliskiren and L-carnitine against isoproterenol-induced cardiac hypertrophy via targeting IL-6/JAK2/STAT3/SOCS3 signaling pathway.

Conflict of interest: All authors declared no conflict of interest. 
Ethical approval: Animal experiments were approved by Animal Ethics Committee of the Faculty of Pharmacy, Al-Azhar University, Egypt. (Approval number: 77/2016).

Author contribution: MH; Performed the experiments, collected the data, analyzed the data, performed the graphical and statistical analysis; NA; Developed the research idea, designed the experiments, supervised the experiment execution, supervised the data analysis, and wrote and revised the manuscript; $\mathbf{A B}$; Supervised the experiment execution, supervised the data analysis and revised the manuscript. All authors read and approved the manuscript, and all data were generated in-house and that no paper mill was used.

Acknowledgements: Special thanks to Dr. Adel Bakeer, professor of pathology, Cairo University, for his great effort and assistance in the histopathological examination of the heart tissue and his valuable comments.

Funding: The authors did not receive support from any organization for the submitted work.

\section{REFERENCES}

1. 1. Schirone L, Forte M, Palmerio S, Yee D, Nocella C, Angelini F, Pagano F, Schiavon S, Bordin A, Carrizzo A, Vecchione C, Valenti V, Chimenti I, De Falco E, Sciarretta S, Frati G. A review of the molecular mechanisms underlying the development and progression of cardiac remodeling. Oxid Med Cell Longev. 2017 July:1-16

https://doi.org/10.1155/2017/3920195 PMID:28751931

2. 2. Wu QQ, Xiao Y, Yuan Y, Ma ZG, Liao HH, Liu C, Zhu J, Yang Z, Deng W, Tang Q. Mechanisms contributing to cardiac remodelling. Clin Sci (Lond). 2017 Aug;131(18):2319-45. https://doi.org/10.1042/CS20171167 PMID:28842527

3. 3. Schiattarella GG, Hill JA. Inhibition of hypertrophy is a good therapeutic strategy in ventricular pressure overload. Circulation. 2015 Apr;131(16):1435-47. https://doi.org/10.1161/CIRCULATIONAH A.115.013894 PMID:25901069
4. 4. Al-Rasheed NM, Al-Oteibi MM, AlManee RZ, Al-Shareef SA, Al-Rasheed NM, Hasan IH, et al. Simvastatin prevents isoproterenol-induced cardiac hypertrophy through modulation of the JAK/STAT pathway. Drug Des Devel Ther. 2015 Jun;9:3217-29.

https://doi.org/10.2147/DDDT.S86431 PMID:26150695

5. 5. Schindler C, Darnell JE Jr. Transcriptional responses to polypeptide ligands: the JAK-STAT pathway. Annu Rev Biochem. 1995;64:621-51. https://doi.org/10.1146/annurev.bi.64.07019 5.003201 PMID:7574495

6. 6. Favoino E, Prete M, Catacchio G, Ruscitti P, Navarini L, Giacomelli R, Perosa F. Working and safety profiles of JAK/STAT signaling inhibitors. Are these small molecules also smart? Autoimmun Rev. 2021 Mar; 20(3):1-13.

https://doi.org/10.1016/j.autrev.2021.10275 0 PMID:33482338

7. 7. Boengler K, Buechert A, Heinen Y, Roeskes C, Hilfiker-Kleiner D, Heusch G, et al. Cardioprotection by ischemic postconditioning is lost in aged and STAT3-deficient mice. Circ Res. 2008 Jan;102(1):131-5.

https://doi.org/10.1161/CIRCRESAHA.107 $\underline{.164699}$ PMID: 17967780

8. 8. Rane SG, Reddy EP. Janus kinases: components of multiple signaling pathways. Oncogene. 2000 Nov;19(49):5662-79. https://doi.org/10.1038/sj.onc.1203925 PMID:11114747

9. 9. Stark GR, Kerr IM, Williams BR, Silverman RH, Schreiber RD. How cells respond to interferons. Annu Rev Biochem. 1998;67:227-64.

https://doi.org/10.1146/annurev.biochem.67 .1 .227 PMID:9759489

10. 10. Darnell JE Jr. STATs and gene regulation. Science. 1997

Sep;277(5332):1630-5.

https://doi.org/10.1126/science.277.5332.16 30 PMID:9287210

11. 11. Starr R, Willson TA, Viney EM, Murray LJ, Rayner JR, Jenkins BJ, et al. A 
family of cytokine-inducible inhibitors of signalling. Nature. 1997

Jun;387(6636):917-21.

https://doi.org/10.1038/43206

PMID:9202125

12. 12. Jatiani SS, Baker SJ, Silverman LR, Reddy EP. Jak/STAT pathways in cytokine signaling and myeloproliferative disorders: approaches for targeted therapies. Genes Cancer. 2010 Oct;1(10):979-93. https://doi.org/10.1177/1947601910397187 PMID:21442038

13. 13. Calegari VC, Bezerra RM, Torsoni MA, Torsoni AS, Franchini KG, Saad MJ, et al. Suppressor of cytokine signaling 3 is induced by angiotensin II in heart and isolated cardiomyocytes, and participates in desensitization. Endocrinology. 2003 Oct;144(10):4586-96. https://doi.org/10.1210/en.2003-0046 PMID:12960061

14. 14. Ji Y, Wang Z, Li Z, Li K, Le X, Zhang $\mathrm{T}$. Angiotensin II induces angiogenic factors production partly via AT1/JAK2/STAT3/SOCS3 signaling pathway in MHCC97H cells. Cell Physiol Biochem. 2012;29(5-6):863-74. https://doi.org/10.1159/000171034 PMID:22613986

15. 15. Zapparoli A, Calegari V, Velloso LA, Guadagnini D, Boer PA, Gontijo JA. Hypothalamic SOCS-3 expression and the effect of intracerebroventricular angiotensin II injection on water intake and renal sodium handling in SHR. J Physiol Sci. 2010 Nov;60(6):425-33. https://doi.org/10.1007/s12576-010-0112-0 PMID:20848345

16. 16. Baker KM, Singeer HA, Aceto JF. Angiotensin II receptor stimulation of cytosolic free calcium and inositol phosphates in chick myocytes. J. Pharmacol. Exp. Ther. 1989,251 (2), 578585.

doi: http://jpet.aspetjournals.org/content/25 $\underline{1 / 2 / 578}$

17. 17. Wood JM, Maibaum J, Rahuel J, Grütter MG, Cohen NC, Rasetti V, et al. Structure-based design of aliskiren, a novel orally effective renin inhibitor. Biochem Biophys Res Commun. 2003
Sep;308(4):698-705.

https://doi.org/10.1016/s0006291x(03)01451-7 PMID:12927775

18. 18. Zhao Z, Li R, Wang X, Li J, Yuan M, Liu E, et al. Attenuation of atrial remodeling by aliskiren via affecting oxidative stress, inflammation and PI3K/Akt signaling pathway. Cardiovasc Drugs Ther. 2020 May: 1-12 https://doi.org/10.1007/s10557-020-07002z PMID:32462265

19. 19. Bin-Dayel AF, Abdel Baky NA, Fadda LM, Mohammad RA, Al-Mohanna F. Effect of aliskiren and carvedilol on expression of $\mathrm{Ca}(2+)$ /calmodulin-dependent protein kinase II $\delta$-subunit isoforms in cardiac hypertrophy rat model. Toxicol Mech Methods. 2016 Feb;26(2):122-31. https://doi.org/10.3109/15376516.2015.112 8035 PMID:26982530

20. 20. Jones LL, McDonald DA, Borum PR. Acylcarnitines: role in brain. Prog Lipid Res. 2010 Jan;49(1):61-75.

https://doi.org/10.1016/j.plipres.2009.08.00 4 PMID:19720082

21. 21. Cahova M, Chrastina P, Hansikova $H$, Drahota Z, Trnovska J, Skop V, et al. Carnitine supplementation alleviates lipid metabolism derangements and protects against oxidative stress in non-obese hereditary hypertriglyceridemic rats. Appl Physiol Nutr Metab. 2015 Mar;40(3):280 91. https://doi.org/10.1139/apnm-20140163 PMID:25723909

22. 22. Aziz MM, Abd El Fattah MA, Ahmed KA, Sayed HM. Protective effects of olmesartan and 1-carnitine on doxorubicininduced cardiotoxicity in rats. Can J Physiol Pharmacol. 2020 Apr;98(4):183-93. https://doi.org/10.1139/cjpp-2019-0299 PMID:31665614

23. 23. McCann MR, George De la Rosa MV, Rosania GR, Stringer KA. L-Carnitine and Acylcarnitines: Mitochondrial Biomarkers for Precision Medicine. Metabolites. 2021 Jan;11(1):1-21. Doi: 10.3390/metabo11010051

24. 24. W.A. Alanazi, N.O. Al-Harbi, F. Imam, M.A. Ansari, A. Alhoshani, A.F. Alasmari, F. Alasmari, M.M. Alanazi, N. Ali. Role of 
carnitine in regulation of blood pressure (MAP/SBP) and gene expression of cardiac hypertrophy markers $(\alpha / \beta$-mhc) during insulin-induced hypoglycaemia: role of oxidative stress. clin exp pharmacol physiol. 2021 Apr;48(4):478-489. doi: 10.1111/1440-1681.13455.

25. 25. Izgüt-Uysal VN, Ağaç A, Derin N. Effect of L-carnitine on carrageenaninduced inflammation in aged rats. Gerontology. 2003 Sep-Oct;49(5):287-92. https://doi.org/10.1159/000071709 PMID:12920348

26. 26. Mollica G, Senesi P, Codella R, Vacante F, Montesano A, Luzi L, et al. Lcarnitine supplementation attenuates NAFLD progression and cardiac dysfunction in a mouse model fed with methionine and choline-deficient diet. Dig Liver Dis. 2020 Mar;52(3):314-23. https://doi.org/10.1016/j.dld.2019.09.002 PMID:31607566

27. 27. Chowdhury D, Tangutur AD, Khatua TN, Saxena P, Banerjee SK, Bhadra MP. A proteomic view of isoproterenol induced cardiac hypertrophy: prohibitin identified as a potential biomarker in rats. J Transl Med. 2013 May;11:1-13. https://doi.org/10.1186/1479-5876-11-130 PMID:23706090

28. 28. Parodi-Rullan R, Barreto-Torres G, Ruiz L, Casasnovas J, Javadov S. Direct renin inhibition exerts an anti-hypertrophic effect associated with improved mitochondrial function in post-infarction heart failure in diabetic rats. Cell Physiol Biochem. 2012;29(5-6):841-50. https://doi.org/10.1159/000178526 PMID:22613984

29. 29. Rauchová H, Dobesová Z, Drahota Z, Zicha J, Kunes J. The effect of chronic Lcarnitine treatment on blood pressure and plasma lipids in spontaneously hypertensive rats. Eur J Pharmacol. 1998 Jan;342(23):235-9. https://doi.org/10.1016/s00142999(97)01505-7 PMID:9548391

30. 30. Liu X, Li B, Wang W, Zhang C, Zhang M, Zhang Y, Xia Y, Dong Z, Guo Y, An F. Effects of HMG-CoA reductase inhibitor on experimental autoimmune myocarditis.
Cardiovasc Drugs Ther. 2012

Apr;26(2):121-30.

https://doi.org/10.1007/s10557-012-6372-6

PMID:22382902

31. 31. Hubbard SR. Mechanistic insights into regulation of JAK2 tyrosin kinase. Front Endocrinol (Lausanne). 2018;8(361):1-7. https://doi.org/10.3389/fendo.2017.00361 PMID:29379470

32. 32. Darnell JE Jr, Kerr IM, Stark GR. JakSTAT pathways and transcriptional activation in response to IFNs and other extracellular signaling proteins. Science. 1994 Jun;264(5164):1415-21.

https://doi.org/10.1126/science.8197455 PMID:8197455

33. 33. Ihle JN. Cytokine receptor signalling. Nature. 1995 Oct;377(6550):591-4. https://doi.org/10.1038/377591a0 PMID:7566171

34. 34. Hirota H, Yoshida K, Kishimoto T, Taga T. Continuous activation of gp130, a signal-transducing receptor component for interleukin 6-related cytokines, causes myocardial hypertrophy in mice. Proc Natl Acad Sci USA. 1995 May;92(11):4862-6. https://doi.org/10.1073/pnas.92.11.4862 PMID:7539136

35. 35. Levison DA. Book reviews: theory and practice of histological techniques. 4 th edition. The J. pathology.1997, 183(2)243244 doi:

https://doi.org/10.1002/(SICI)10969896(199710)183:2<243:AID-

PATH770>3.0.CO;2-F

36. 36. de Lemos JA, McGuire DK, Drazner $\mathrm{MH}$. B-type natriuretic peptide in cardiovascular disease. Lancet. 2003 Jul;362(9380):316-22.

https://doi.org/10.1016/S01406736(03)13976-1 PMID:12892964

37. 37. Selvaraj P, Pugalendi KV. Hesperidin, a flavanone glycoside, on lipid peroxidation and antioxidant status in experimental myocardial ischemic rats. Redox Rep. 2010;15(5):217-23.

https://doi.org/10.1179/135100010X128264 46921509 PMID:21062537 
38. 38. Leenen FH, White R, Yuan B. Isoproterenol-induced cardiac hypertrophy: role of circulatory versus cardiac reninangiotensin system. Am J Physiol Heart Circ Physiol. 2001 Dec;281(6):H2410-6. https://doi.org/10.1152/ajpheart.2001.281.6. $\underline{\mathrm{H} 2410}$ PMID:11709406

39. 39. Yeh JL, Hsu JH, Wu PJ, Liou SF, Liu $\mathrm{CP}$, Chen IJ, et al. KMUP-1 attenuates isoprenaline-induced cardiac hypertrophy in rats through $\mathrm{NO} / \mathrm{cGMP} / \mathrm{PKG}$ and ERK1/2/calcineurin A pathways. Br J Pharmacol. 2010 Mar;159(5):1151-60. https://doi.org/10.1111/j.14765381.2009.00587.x PMID:20132211

40. 40. Yang NI, Liao CC, Hung MJ, Cherng WJ. Acta. Direct renin inhibitor attenuates left ventricular remodeling in postmyocardial infarction heart failure mice. Acta Cardiol Sin. 2013 Mar;29(2):160-7. PMID:27122700

41. 41. Rashikh A, Ahmad SJ, Pillai KK, Kohli K, Najmi AK. Aliskiren attenuates myocardial apoptosis and oxidative stress in chronic murine model of cardiomyopathy. Biomed Pharmacother. 2012

Mar;66(2):138-43. https://doi.org/10.1016/j.biopha.2011.11.02 0 PMID:22386366

42. 42. Song X, Qu H, Yang Z, Rong J, Cai W, Zhou H. Efficacy and safety of L-carnitine treatment for chronic heart failure: a metaanalysis of randomized controlled trials. BioMed Res Int. 2017:1-11. https://doi.org/10.1155/2017/6274854 PMID:28497060

43. 43. Mate A, Miguel-Carrasco JL, Vázquez $\mathrm{CM}$. The therapeutic prospects of using Lcarnitine to manage hypertension-related organ damage. Drug Discov Today. 2010 Jun;15(11-12):484-92. https://doi.org/10.1016/j.drudis.2010.03.014 PMID:20363359

44. 44. Wong AP, Niedzwiecki A, Rath M. Myocardial energetics and the role of micronutrients in heart failure: a critical review. Am J Cardiovasc Dis. 2016 Sep;6(3):81-92. PMID:27679743

45. 45. Mustafa HN, Hegazy GA, Awdan SA, AbdelBaset M. Protective role of CoQ10 or
L-carnitine on the integrity of the myocardium in doxorubicin induced toxicity. Tissue Cell. 2017 Jun;49(3):41026.

https://doi.org/10.1016/j.tice.2017.03.007 PMID:28410798

46. 46. Cai L, Kang YJ. Oxidative stress and diabetic cardiomyopathy: a brief review. Cardiovasc Toxicol. 2001;1(3):181-93. https://doi.org/10.1385/CT:1:3:181 PMID:12213971

47. 47. Yin $\mathrm{W}$, Zhang $\mathrm{P}$, Huang JH, Zhang QY, Fan R, Li J, et al. Stimulation of kappaopioid receptor reduces isoprenalineinduced cardiac hypertrophy and fibrosis. Eur J Pharmacol. 2009 Apr;607(1-3):13542.

https://doi.org/10.1016/j.ejphar.2009.01.050 PMID:19233160

48. 48. Naugle JE, Olson ER, Zhang X, Mase SE, Pilati CF, Maron MB, et al. Type VI collagen induces cardiac myofibroblast differentiation: implications for postinfarction remodeling. Am J Physiol Heart Circ Physiol. 2006 Jan;290(1):H32330 .

https://doi.org/10.1152/ajpheart.00321.2005 PMID:16143656

49. 49. Weber KT, Sun Y, Bhattacharya SK, Ahokas RA, Gerling IC. Myofibroblastmediated mechanisms of pathological remodelling of the heart. Nat Rev Cardiol. 2013 Jan;10(1):15-26.

https://doi.org/10.1038/nrcardio.2012.158 PMID:23207731

50. 50. Oliveira SH, Brito VG, Frasnelli SC, Ribeiro BD, Ferreira MN, Queiroz DP, et al. Aliskiren attenuates the inflammatory response and wound healing process in diabetic mice with periodontal disease. Front Pharmacol. 2019 Jul;10:1-16. https://doi.org/10.3389/fphar.2019.00708 PMID:31333451.

51. 51. Ma L, Hua J, He L, Li Q, Zhou J, Yu J. Anti-fibrotic effect of Aliskiren in rats with deoxycorticosterone induced myocardial fibrosis and its potential mechanism. Bosn J Basic Med Sci. 2012 May;12(2):69-73. https://doi.org/10.17305/bjbms.2012.2498 PMID:22642589 
52. 52. Altarejo Marin T, Machado Bertassoli B, Alves de Siqueira de Carvalho A, Feder D. The use of aliskiren as antifibrotic drug in experimental models: A systematic review. Drug Dev Res. 2020 Feb;81(1):114-26. https://doi.org/10.1002/ddr.21610 PMID:31605544

53. 53. Omori Y, Ohtani T, Sakata Y, Mano T, Takeda Y, Tamaki S, et al. L-Carnitine prevents the development of ventricular fibrosis and heart failure with preserved ejection fraction in hypertensive heart disease. J Hypertens. 2012 Sep;30(9):183444.

https://doi.org/10.1097/HJH.0b013e328356 9c5a PMID:22796714

54. 54. Zheng H, Piao S, Sun L, Zhao H, Jin J, Jin J, Chulwoo Yang C, Li C. Renoprotective effects of Lcarnitine in streptozotocin-induced diabetic nephropathy. Int J ClinExp Med 2018, 11(5),4459-4469.

https://1library.net/title/original-articlerenoprotective-effects-carnitinestreptozotocin-diabetic-nephropathy

55.

56. 55. Zhang C, Wang F, Zhang Y, Kang Y, Wang H, Si M, et al. Celecoxib prevents pressure overload-induced cardiac hypertrophy and dysfunction by inhibiting inflammation, apoptosis and oxidative stress. J Cell Mol Med. 2016 Jan;20 (1):116-27. https://doi.org/10.1111/jcmm.12709 PMID:26512452

57. 56. Abdel Baky NA, Al-Rasheed NM. N.M. AL-Rasheed, I.Y. Zaglol, M.A. Radwan, Alpha-lipoic acid and amlodipine ameliorate myocardial infarction induced by isoproterenol in rats. Int $\mathrm{J}$ Acad Res. 2009;1:68-77.

58. https://www.academia.edu/29698823/Alpha lipoic acid and amlodipine ameliorate myocardial_infarction_induced_by_isoprot erenol in rats

59. 57. Wheatley AM, Thandroyen FT, Opie LH. Catecholamine-induced myocardial cell damage: catecholamines or adrenochrome. J Mol Cell Cardiol. 1985

Apr;17(4):349-59.

https://doi.org/10.1016/S0022-

2828(85)80134-6 PMID:4020875

60. 58. Tojo A, Onozato ML, Kobayashi N, Goto A, Matsuoka H, Fujita T. Angiotensin II and oxidative stress in Dahl Salt-sensitive rat with heart failure. Hypertension. 2002

Dec;40(6):834-9.

https://doi.org/10.1161/01.HYP.000003950 6.43589.D5 PMID:12468566

61. 59. Velez Rueda JO, Palomeque J, Mattiazzi A. Early apoptosis in different models of cardiac hypertrophy induced by high renin-angiotensin system activity involves CaMKII. J Appl Physiol (1985). 2012 Jun;112(12):2110-20. https://doi.org/10.1152/japplphysiol.01383. 2011 PMID:22492934

62. 60. Aboubakr M, Elsayd F, Soliman A, Fadl SE, El-Shafey A, Abdelhiee EY. LCarnitine and vitamin $\mathrm{E}$ ameliorate cardiotoxicity induced by tilmicosin in rats. Environ Sci Pollut Res Int. 2020 Jun;27(18):23026-34. https://doi.org/10.1007/s11356-020-089196 PMID:32329006

63. 61. Chao HH, Liu JC, Hong HJ, Lin JW, Chen $\mathrm{CH}$, Cheng TH. L-carnitine reduces doxorubicin-induced apoptosis through a prostacyclin-mediated pathway in neonatal rat cardiomyocytes. Int J Cardiol. 2011 Jan;146(2):145-52.

https://doi.org/10.1016/j.ijcard.2009.06.010 PMID:19552975

64. 62. Alshahrani S, Rapoport RM, Soleimani M. Vascular contractile reactivity in hypotension due to reduced renal reabsorption of $\mathrm{Na}^{+}$and restricted dietary Na. Naunyn Schmiedebergs Arch Pharmacol. 2017 Mar;390(3):321-6. https://doi.org/10.1007/s00210-017-1340-0 PMID:28108829

65. 63. Whaley-Connell A, Habibi J, Rehmer N, Ardhanari S, Hayden MR, Pulakat L, et al. Renin inhibition and AT(1)R blockade improve metabolic signaling, oxidant stress and myocardial tissue remodeling. Metabolism. 2013 Jun;62(6):861-72. 
https://doi.org/10.1016/j.metabol.2012.12.0 12 PMID:23352204

66. 64. González GE, Rhaleb NE, D’Ambrosio MA, Nakagawa P, Liu Y, Leung P, et al. Deletion of interleukin-6 prevents cardiac inflammation, fibrosis and dysfunction without affecting blood pressure in angiotensin II-high salt-induced hypertension. J Hypertens. 2015 Jan;33(1):144-52. https://doi.org/10.1097/HJH.000000000000 0358 PMID:25304471

67. 65. Ruiz S, Pergola PE, Zager RA, Vaziri ND. Targeting the transcription factor Nrf2 to ameliorate oxidative stress and inflammation in chronic kidney disease. Kidney Int. 2013 Jun;83(6):1029-41. https://doi.org/10.1038/ki.2012.439 PMID:23325084

68. 66. Sharma A, Tate M, Mathew G, Vince JE, Ritchie RH, de Haan JB. Oxidative stress and NLRP3-inflammasome activity as significant drivers of diabetic cardiovascular complications: therap implications. Front Physiol. 2018 20(9): 115.

https://doi.org/10.3389/fphys.2018.00114 PMID:29515457

69. 67. Al-Aubaidy HA, Sahib HA, Mohammad BI, Hadi NR, Abas SM. Antiatherosclerotic potential of aliskiren: its antioxidant and anti-inflammatory effects in rabbits: a randomized controlled trial. J Pharm Technol Drug Res. 2013;2(1):1-7. https://doi.org/10.7243/2050-120X-2-11

70. 68. Aziz TA, Kareem AA, Othman HH, Ahmed ZA. The Anti-Inflammatory Effect of Different Doses of Aliskiren in Rat Models of Inflammation. Drug Des Devel Ther. 2020 Jul;14(14):2841-51. https://doi.org/10.2147/DDDT.S255607 PMID:32764883

71. 69. Lee BJ, Lin JS, Lin YC, Lin PT. Antiinflammatory effects of L-carnitine supplementation $(1000 \mathrm{mg} / \mathrm{d})$ in coronary artery disease patients. Nutrition. 2015 Mar;31(3):475-9. https://doi.org/10.1016/j.nut.2014.10.001 PMID:25701337
72. 70. Ranjbar Kohan N, Nazifi S, Tabandeh MR, Ansari Lari M. Effect of L-carnitine supplementation on apelin and apelin receptor (Apj) expression in cardiac muscle of obese diabetic rats. Cell J. 2018 Oct;20(3):427-34. https://doi.org/10.22074/cellj.2018.5408 PMID:29845798

73. 71. Miguel-Carrasco JL, Mate A, Monserrat MT, Arias JL, Aramburu O, Vázquez CM. The role of inflammatory markers in the cardioprotective effect of L-carnitine in LNAME-induced hypertension. Am J Hypertens. 2008 Nov;21(11):1231-7. https://doi.org/10.1038/ajh.2008.271 PMID:18787523

74. 72. Szczepanek K, Chen Q, Derecka M, Salloum FN, Zhang Q, Szelag M, et al. Mitochondrial-targeted Signal transducer and activator of transcription 3 (STAT3) protects against ischemia-induced changes in the electron transport chain and the generation of reactive oxygen species. $\mathbf{J}$ Biol Chem. 2011 Aug;286(34):29610-20. https://doi.org/10.1074/jbc.M111.226209 PMID:21715323

75. 73. Harris IS, Zhang S, Treskov I, Kovacs A, Weinheimer C, Muslin AJ. Raf-1 kinase is required for cardiac hypertrophy and cardiomyocyte survival in response to pressure overload. Circulation. 2004 Aug;110(6):718-23.

https://doi.org/10.1161/01.CIR.0000138190 .50127.6A PMID: 15289381

76. 74. Shi J, Wei L. Regulation of JAK/STAT signalling by SOCS in the myocardium. Cardiovasc Res. 2012 Dec;96(3):345-7. https://doi.org/10.1093/cvr/cvs321 PMID:23090607

77. 75. Yasukawa H, Hoshijima M, Gu Y, Nakamura T, Pradervand S, Hanada T, et al. Suppressor of cytokine signaling- 3 is a biomechanical stress-inducible gene that suppresses gp130-mediated cardiac myocyte hypertrophy and survival pathways. J Clin Invest. 2001 Nov;108(10):1459-67. https://doi.org/10.1172/JCI13939 PMID:11714737

78. 76. Cittadini A, Monti MG, Iaccarino G, Castiello MC, Baldi A, Bossone E, et al. 
SOCS1 gene transfer accelerates the transition to heart failure through the inhibition of the gp130/JAK/STAT pathway. Cardiovasc Res. 2012 Dec;96(3):381-90. https://doi.org/10.1093/cvr/cvs261 PMID:22875468

79. 77. Fasshauer M, Klein J, Lossner U, Paschke R. Isoproterenol is a positive regulator of the suppressor of cytokine signaling-3 gene expression in 3T3-L1 adipocytes. J Endocrinol. 2002 Dec;175(3):727-33. https://doi.org/10.1677/joe.0.1750727 PMID:12475383

80. 78. Wang Q, Zhou X, Zhang P, Zhao P, Nie L, Ji N, Ding Y, Wang Q. 25Hydroxyvitamin $\mathrm{D}_{3}$ positively regulates periodontal inflammaging via SOCS3/STAT signaling in diabetic mice. Steroids. 2020 Apr;156:1-.10 https://doi.org/10.1016/j.steroids.2019.1085 70 PMID:31917967

81. 79. Mooney RA, Senn J, Cameron S, Inamdar N, Boivin LM, Shang Y, et al. Suppressors of cytokine signaling- 1 and - 6 associate with and inhibit the insulin receptor. A potential mechanism for cytokine-mediated insulin resistance. J Biol Chem. 2001 Jul;276(28):25889-93. https://doi.org/10.1074/jbc.M010579200 PMID:11342531

82. 80. Zaheri Z, Fahremand F, Rezvani ME, Karimollah A, Moradi A. Curcumin exerts beneficial role on insulin resistance through modulation of SOCS3 and Rac-1 pathways in type 2 diabetic rats. J Funct Foods. 2019;60:1-7. https://doi.org/10.1016/j.jff.2019.103430.

83. 81. Yasukawa H, Nagata T, Oba T, Imaizumi T. SOCS3: A novel therapeutic target for cardioprotection. JAK-STAT. 2012 Oct;1(4):234-40. https://doi.org/10.4161/jkst.22435 PMID:24058778

84. 82. Kong F, Guo X, Noel JG, Wells DA, Lovell GJ, Ogle CK. Thermal injuryinduced increases of hepatocyte SOCS3 lead to decreases in STAT3.Shock 2002,
18(4):374-379. doi: 10.1097/00024382200210000-00014

85. 83. Calegari VC, Bezerra RM, Torsoni MA, Torsoni AS, Franchini KG, Saad MJ, et al. Suppressor of cytokine signaling 3 is induced by angiotensin II in heart and isolated cardiomyocytes, and participates in desensitization. Endocrinology. 2003 Oct;144(10):4586-96. https://doi.org/10.1210/en.2003-0046 PMID:12960061

86. 84. Stephanou A. Role of STAT-1 and STAT-3 in ischaemia/reperfusion injury. J Cell Mol Med. 2004 Oct-Dec;8(4):519-25. https://doi.org/10.1111/j.15824934.2004.tb00476.x PMID:15601580

87. 85. Sharifi AM, Ghaderpanahi M, Mazhari SZ. The effect of L-carnitine on serum nitric oxide level and angiotensin converting enzyme activity in STZ-Induced diabetic and normal rats. Iran. J. Diab. Lip. Dis. 2007, 6(3): 225-234.

http://ijdld.tums.ac.ir/article-1-314-en.html

88. 86. Wood JM, Maibaum J, Rahuel J, Grütter MG, Cohen NC, Rasetti V, et al. Structure-based design of aliskiren, a novel orally effective renin inhibitor. Biochem Biophys Res Commun. 2003 Sep;308(4):698-705. https://doi.org/10.1016/S0006$\underline{\text { 291X(03)01451-7 PMID:12927775 }}$ 